\title{
Influence of gravity compensation on kinematics and muscle activation patterns during reach and retrieval in subjects with cervical spinal cord injury: An explorative study
}

\author{
Marieke G. M. Kloosterman, PT, MSc; ${ }^{1-2 *}$ Govert J. Snoek, MD, PhD; ${ }^{2-3}$ Mirjam Kouwenhoven, MD; ${ }^{2-3}$ \\ Anand V. Nene, MD, PhD; ${ }^{2-3}$ Michiel J. A. Jannink, PhD ${ }^{2,4}$ \\ ${ }^{1}$ Center for Human Movement Sciences, University Medical Center Groningen, University of Groningen, Groningen, \\ the Netherlands; ${ }^{2}$ Roessingh Research and Development, Enschede, the Netherlands; ${ }^{3}$ Roessingh Rehabilitation Cen- \\ ter, Enschede, the Netherlands; ${ }^{4}$ Laboratory of Biomechanical Engineering, University of Twente, Faculty of Engineer- \\ ing Technology, Enschede, the Netherlands
}

\begin{abstract}
Many interventions in upper-limb rehabilitation after cervical spinal cord injury (CSCI) use arm support (gravity compensation); however, its specific effects on kinematics and muscle activation characteristics in subjects with a CSCI are largely unknown. We conducted a cross-sectional explorative study to study these effects. Nine subjects with a CSCI performed two goal-directed arm movements (maximal reach, reach and retrieval) with and without gravity compensation. Angles at elbow and shoulder joints and muscle activation were measured and compared. Seven subjects reduced elbow extension (range $1.8^{\circ}-4.5^{\circ}$ ) during the maximal reaching task with gravity compensation. In the reach and retrieval task with gravity compensation, all subjects decreased elbow extension (range $0.1^{\circ}-11.0^{\circ}$ ). Eight subjects executed movement closer to the body. Regarding muscle activation, gravity compensation did not influence timing; however, the amplitude of activation decreased, especially in antigravity muscles, namely mean change $+/-$ standard deviation of descending part of trapezius $(18.2 \%+/-37.5 \%)$, anterior part of deltoid $(37.7 \%+/-16.7 \%)$, posterior part of deltoid $(32.0 \%+/-13.9 \%)$, and long head biceps (49.6\% +/- 20.0\%). Clinical implications for the use of gravity compensation in rehabilitation (during activities of daily living or exercise therapy) should be further investigated with a larger population.
\end{abstract}

Key words: electromyography, goal-directed movements, gravity compensation, kinematics, rehabilitation, robot-assisted therapy, robotics, spinal cord injury, tetraplegia, upper limb.

\section{INTRODUCTION}

Damage to the spinal cord causes loss of motor and sensory function of the body parts below the level of the lesion. In patients with a cervical spinal cord injury (CSCI), the arm and hand function is affected to varying degrees according to the level and completeness of the lesion [1]. Compared with other spinal cord injury-related impairments, improvement in upper-limb function is one of the highest priorities in patients with a CSCI [2]. Exercise therapy integrated in an intensive rehabilitation program to learn or relearn motor functions is considered very important in optimizing the remaining upper-limb function [1,3]. Even in the chronic stage, intensive exercise therapy positively affects upper-limb motor control and functional abilities in patients with a CSCI [4].

Abbreviations: $3-\mathrm{D}=$ three dimensional, $\mathrm{ADL}=$ activity of daily living, $\mathrm{CSCI}=$ cervical spinal cord injury, $\mathrm{MRC}=$ Medical Research Council, sEMG = surface electromyography.

*Address all correspondence to Marieke G. M. Kloosterman, PT, MSc; Roessingh Research and Development, Roessinghsbleekweg 33b, 7522 AH Enschede, the Netherlands; +3153-487-5777; fax: +31-53-434-0849.

Email: m.kloosterman@rrd.nl

DOI:10.1682/JRRD.2010.02.0014 
Literature indicates that motor learning or relearning is influenced by several key elements: active movements, intensity of practice (frequency, repetitions, and duration), use of feedback, task specificity, goal-orientated practice, and variation [5-6]. Exercise therapy based on these motor learning or relearning principles asks great physical effort from patients with a CSCI who have impaired upper-limb function. We presume that during goal-directed movements, a large part of the preserved muscle force is required to hold the arm against gravity; consequently, less muscle force is available to perform the actual movements. To facilitate goal-directed arm movements during activities of daily living (ADLs) [7] or exercise therapy, therapeutic devices are often used to support the weight of the arm (e.g., with the Swedish Help Arm [Kinsman Enterprises, Inc; West Frankfort, Illinois]). In the last decade, several innovative therapeutic devices, including robotics, have been developed to support the affected upper limb during exercise therapy [8-9]. In these robotic devices, different treatment modalities have been implemented, such as passive, active-assisted, and active-resisted movements [8]; consequently, gravity compensation is incorporated in the design [8-9]. Until now, the effect of gravity compensation on motor control and functional abilities has mainly been investigated in nondisabled elderly [10] and stroke patients [11-15]. Although many applications in rehabilitation after a spinal cord injury include gravity compensation during ADLs or exercise therapy, the specific effects on kinematics and muscle activation characteristics (amplitude and timing) in patients with a CSCI are largely unknown. A cross-sectional explorative study that measured kinematics and surface electromyography (sEMG) during goal-directed movements with and without gravity compensation was conducted to study the effects of gravity compensation in subjects with a CSCI.

\section{METHODS}

\section{Subjects}

Nine subjects with a CSCI (at least 1 year since injury) were recruited from a local rehabilitation center. Inclusion criteria for participation were motor injury level C5-C7 (cervical) and age between 18 and 65 years. Exclusion criteria were extreme shoulder pain, contractures of the upper limb, and/or spasticity preventing performance of the required tasks. All subjects were assessed according to the standard neurological classification [16].

\section{Apparatus}

A mechanical, passive device called Freebal [17] (University of Twente, Enschede, the Netherlands; now available commercially as ArmeoBoom, Hocoma; Volketswil, Switzerland) was used to counteract the effect of gravity on the upper limb (Figure 1). The device has two slings - one is applied at the elbow and the other around

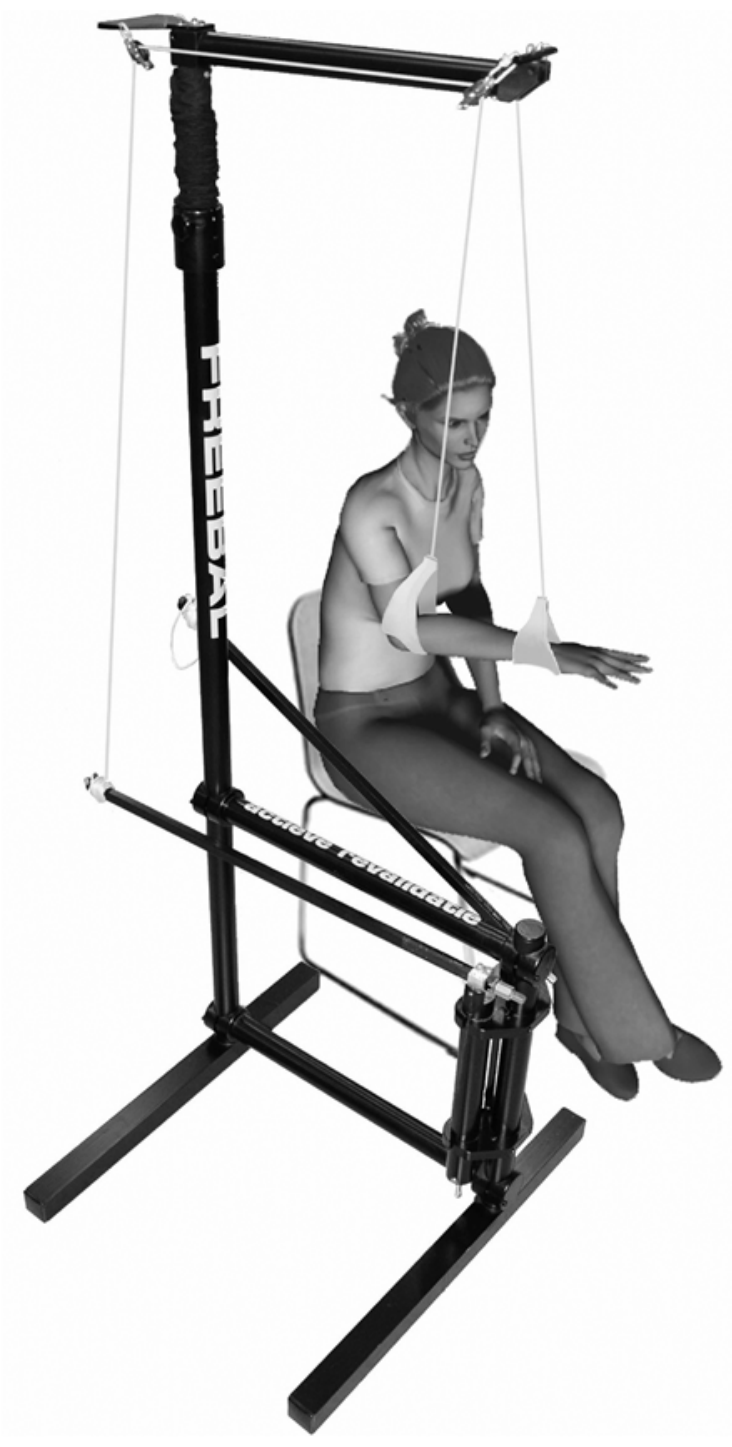

Figure 1.

Freebal device for gravity compensation of upper limb. Source: Stienen AH, Hekman EE, Van der Helm FC, Prange GB, Jannink MJ, Aalsma AM, Van der Kooij H. Freebal: Dedicated gravity compensation for the upper extremities. In: Proceedings of the 2007 IEEE 10th International Conference on Rehabilitation Robotics; 2007 Jun 13-15; Noordwijk aan Zee, the Netherlands. Piscataway (NJ): IEEE Press. p. 804-8. DOI:10.1109/ICORR.2007.4428517 
the wrist. Each sling is connected to an independent adjustable spring by way of an overhead cable and pulleys. During the goal-directed movements, this system enables a constant amount of support throughout the three-dimensional (3-D) working volume, irrespective of the position and orientation of the arm [17].

\section{Procedures}

During the measurements, subjects sat in their own wheelchairs (one subject was not wheelchair-dependent and sat on a normal chair) in front of a height adjustable table. In the starting position, subjects sat with their forearm flat on the tabletop, elbow flexed at $90^{\circ}$, and hand on the starting dot. Subjects performed two goal-directed movements with and without the Freebal:

1. Maximal reaching task. This task consisted of three maximum reaches in front of the subjects, without gliding the hand and arm along the tabletop.

2. Reach and retrieval task. Subjects were instructed to move at their own comfortable speed between a starting dot and target dot on the table for 30 seconds. Both dots were $10 \mathrm{~cm}$ in diameter, and the distance between the dots was $35 \mathrm{~cm}$ (Figure 2(a)).

\section{Measurement and Data Analysis}

\section{Kinematics}

Kinematics were recorded with a 3-D optical movement tracking system with six cameras (Vicon Nexus 1.3.109, Oxford Metrics Ltd; Oxford, United Kingdom). Reflective markers were placed on 10 bony landmarks of the arm and trunk: processus spinosus of the seventh cervical and eighth thoracic vertebra, incisura jugularis, processus xiphoideus, acromioclavicular joint, medial and lateral epicondyle, radial and ulnar styloid, and distal head third metacarpal (Figure 2(b)). Six cameras at $100 \mathrm{~Hz}$ recorded the 3-D marker trajectories. The acromion marker was used for estimating the glenohumeral rotation center. Scapular motion was disregarded because scapular motion was not likely to participate in the anteflexion movement if the angle of elevation remains below $60^{\circ}$.

The marker trajectories were visually inspected for recording errors and missing marker data. If one trunk marker was missing, we replaced it using the Vicon BodyBuilder model (Metrics Ltd; Oxford, United Kingdom). This model estimated the position of the missing marker by the position of the other three markers. We

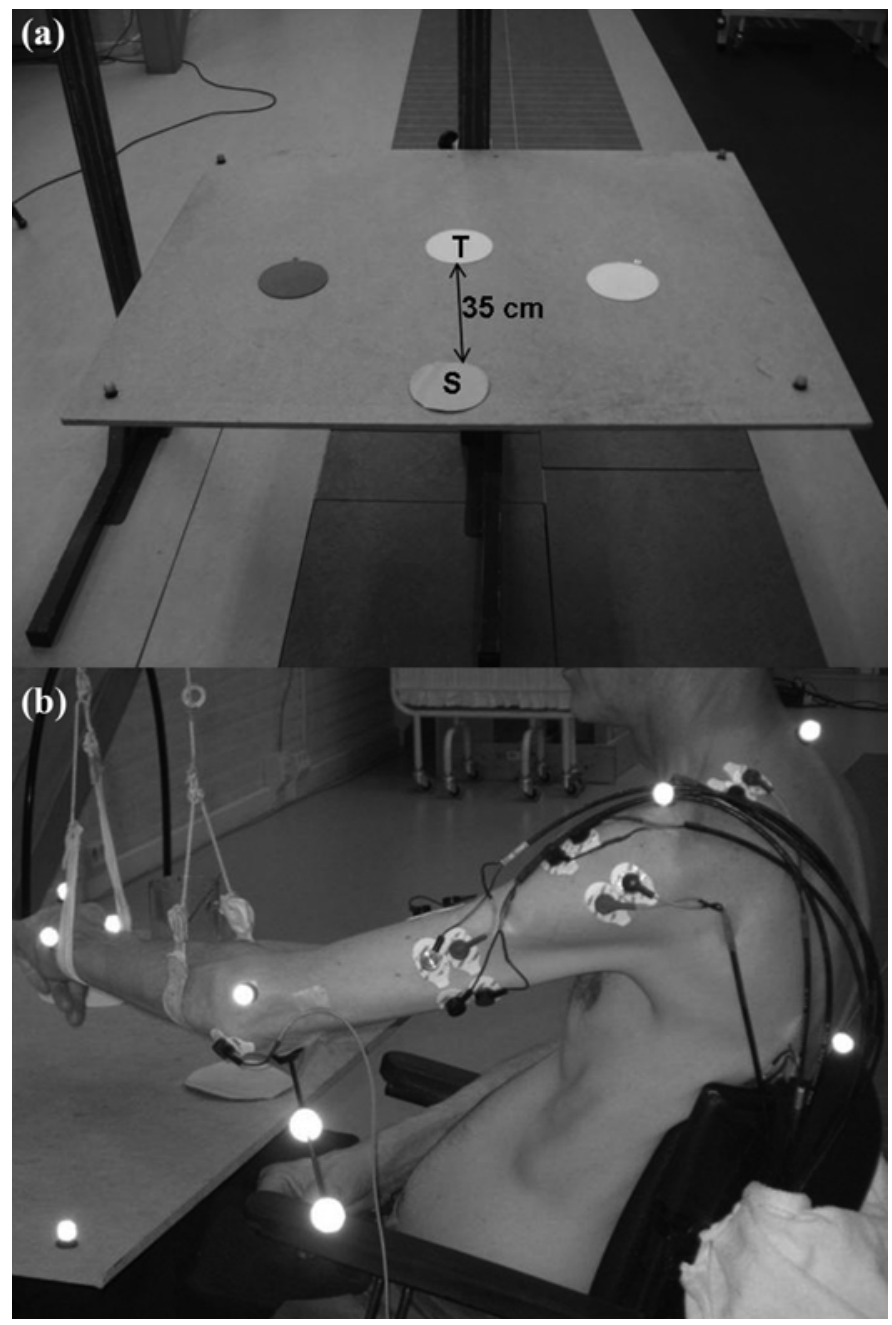

Figure 2.

(a) Tabletop with start and target dots and (b) experimental setup. $\mathrm{S}=$ starting dot, $\mathrm{T}=$ target dot.

replaced missing marker trajectories over a short period (less than 10 samples) by linear interpolation. If data were missing for longer periods or at the end of the reach or retrieval movement, the movement cycle was removed.

Marker position data were converted to limb segments data according to the guidelines of the International Society of Biomechanics [18]; thereafter, joint angles were calculated with Euler rotation. The elbow joint angle (Figure 3(a)) was specified as the angle between the longitudinal axis of the upper arm and the forearm (full elbow extension was defined as $0^{\circ}$; forearm perpendicular to upper arm, $90^{\circ}$ ). We calculated two angles to describe the position of the upper arm related to the thorax: (1) the angle of elevation (Figure 3(b)), 
(a)

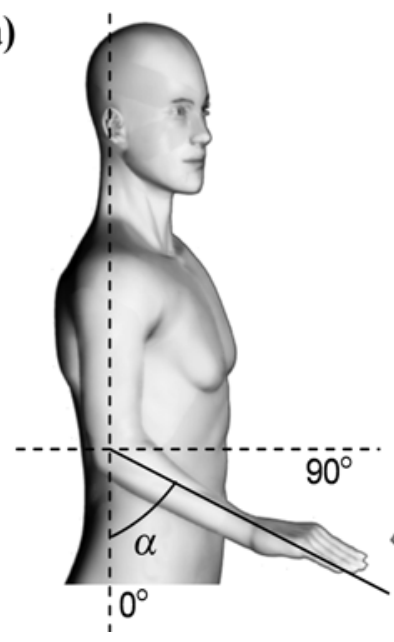

(b)

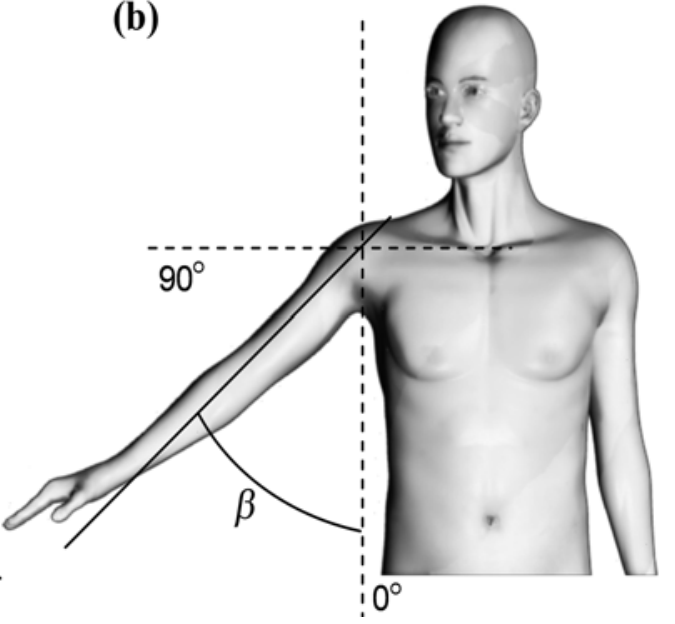

(c)

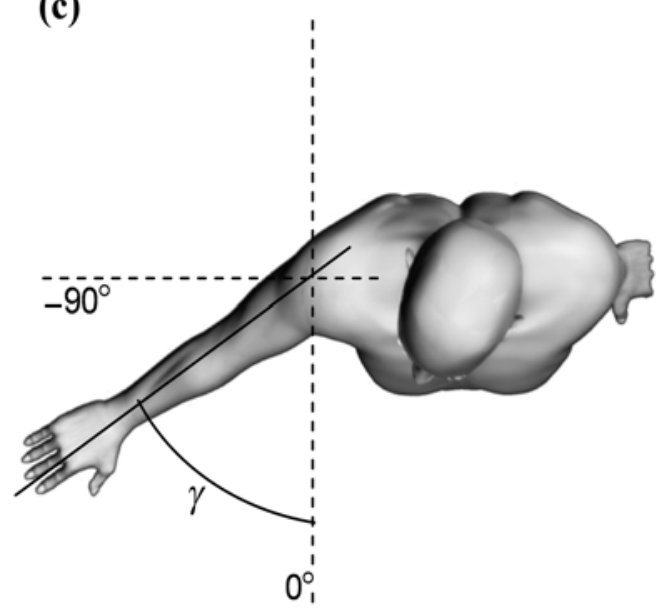

Figure 3.

Representations of calculated angles to express position of elbow and shoulder in accordance with recommendations of International Society of Biomechanics: (a) elbow angle $(\alpha)$, (b) angle of elevation $(\beta)$, and (c) plane of elevation $(\gamma)$.

defined as the angle between the upper arm and trunk (upper arm parallel with thorax, $0^{\circ}$; upper arm parallel with horizontal; $90^{\circ}$ ), and (2) the plane of elevation (Figure 3(c)), defined as the angle between the thorax and the upper arm in the transversal plane (arm extended forward, $0^{\circ}$; arm extended to the lateral, $-90^{\circ}$ ).

For the maximal reaching task, we compared the maximum elbow extension with and without gravity compensation. To quantify the differences between the reach and retrieval task with and without gravity compensation, we derived joint rotations (in degrees) of the angles just mentioned and parameters of the movement cycles (mean duration of one movement cycle, number of repetitions within 30 seconds). Cycle parameters were averaged over all movement cycles within a series; the first two cycles were excluded for analysis. A movement cycle consisted of two parts, namely reach (maximum to minimum elbow angle) and retrieval (minimum to maximum elbow angle).

\section{Electromyography}

Bipolar sEMG of eight superficial muscles (descending parts of the trapezius, anterior and posterior parts of the deltoid, pectoralis major, long head of the biceps, long head and lateral head of the triceps, and latissimus dorsi) was recorded with circular, wet gel, silver/silverchloride electrodes (ARBO, type S93SG, Tyco/Healthcare Deutschland; Neustadt/Donau, Germany) at a sample frequency of $1,000 \mathrm{~Hz}$. Electrode placement, skin preparation, and recording protocol were in accordance with the SENIAM guidelines [19].

sEMG signals were synchronized with the marker trajectories (Figure 4). The time axis was normalized from 0 to 100 percent: reach 0 to 50 percent and retrieval 51 to 100 percent.

We converted the band-pass filtered sEMG signals to smooth rectified sEMG using a second-order Butterworth filter with frequency at $25 \mathrm{~Hz}$. To visualize the differences in smooth rectified sEMG, we plotted movement trajectories (averaged data over all cycles) for two subjects with and without gravity compensation plotted in the same graph (Figure 5). Changes in the amplitude of muscle activation during movements with gravity compensation were expressed as a percentage of the change of the area under the curve of the same movement without gravity compensation. The area under the curve is calculated as the integral of the smooth rectified sEMG.

Timing of muscle activation was analyzed visually. The primary investigator assessed the sEMG recordings, and a coauthor with extensive experience in SEMG analysis checked it.

\section{Statistical Analysis}

This study had an explorative character; therefore, the effect of gravity compensation was described separately for each individual subject. Because of the small sample size and a heterogeneous population, a Wilcoxon signed rank test was performed and the median or ranges were 


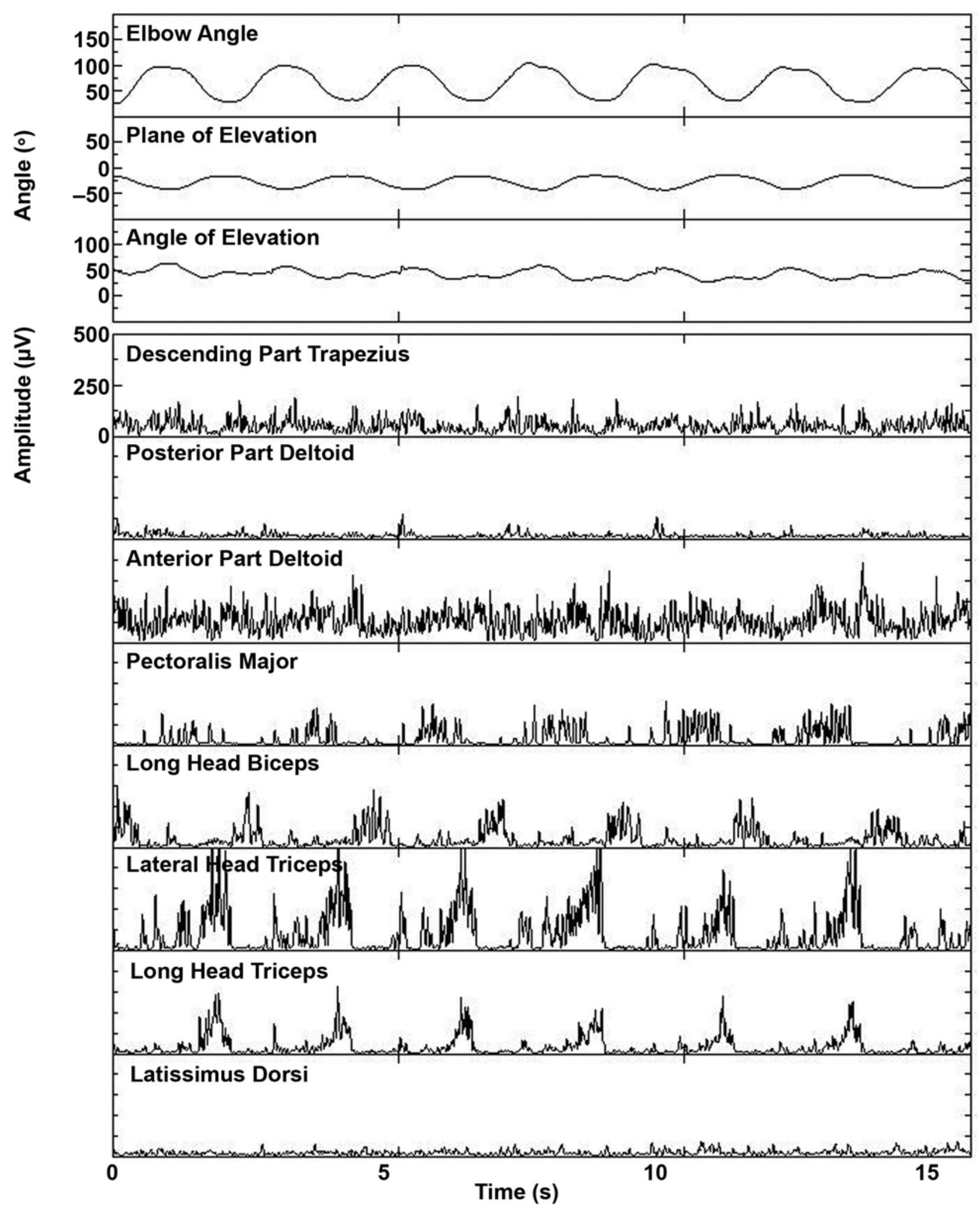

Figure 4.

Elbow and shoulder joint angles $\left(^{\circ}\right)$ during 15 s repetitive reach and retrieval tasks with Freebal, performed by subject with identification number 2, simultaneously displayed with smooth rectified surface electromyography values (microvolt) of eight measured muscles. 


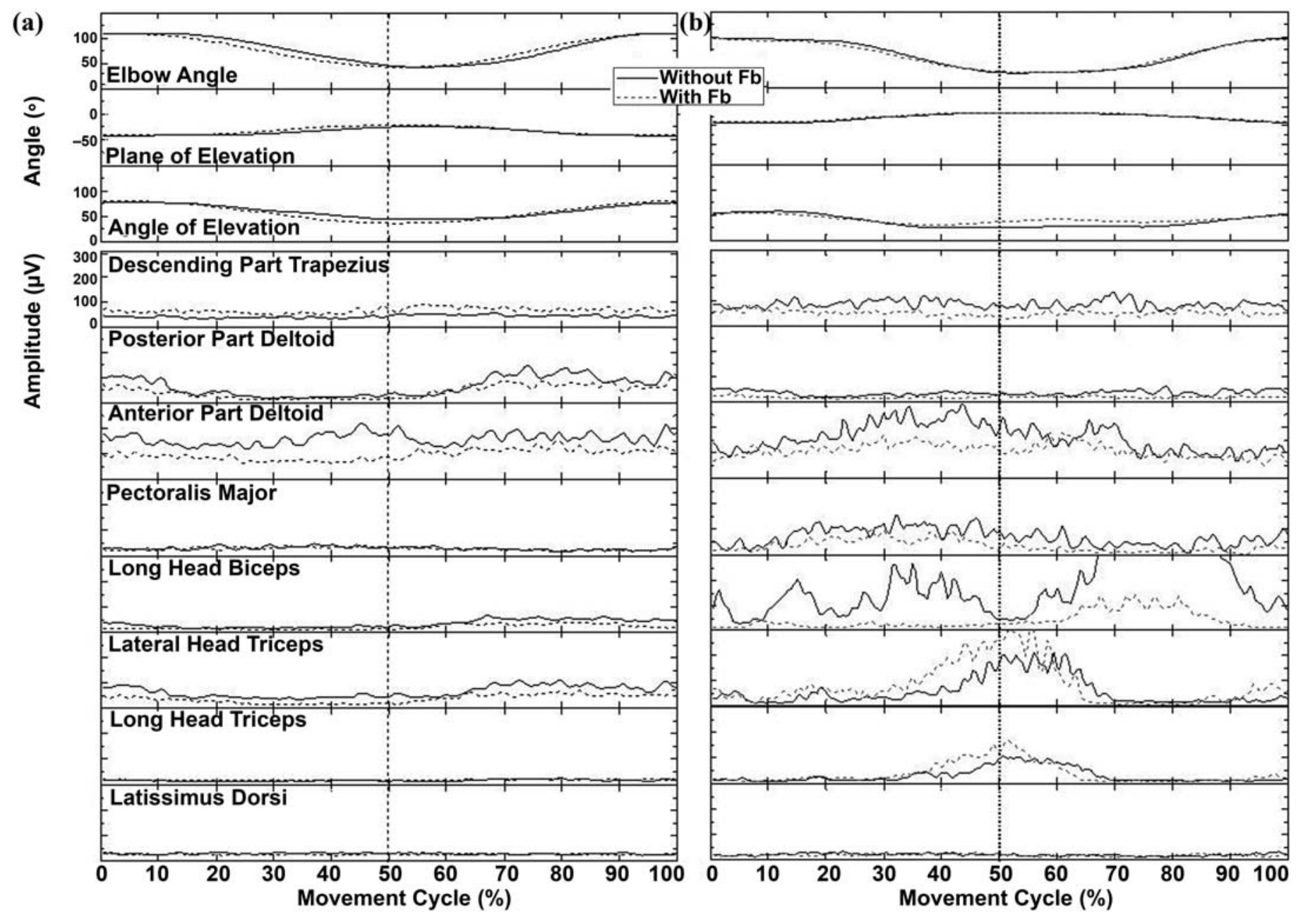

Figure 5.

Mean muscle activation pattern of reach and retrieval task with and without Freebal (Fb). Conditions with (dotted line) and without (solid line) gravity compensation were plotted in same graph. Smooth rectified surface electromyography (sEMG) (microvolt) of eight measured muscles and corresponding joint angles $\left({ }^{\circ}\right)$ was plotted against average movement cycle, divided into reach (1\%-50\%) and retrieval (51\%-100\%). (a) Activation patterns of subject with identification (ID) number 9. Amplitude of sEMG of antigravity muscles decreased with use of Fb, except descending part of trapezius. (b) Activation pattern of subject with ID number 2. Amplitude of sEMG of antigravity muscles decreased and amplitude of sEMG in triceps increased with use of $\mathrm{Fb}$.

found. From the Wilcoxon test, the test statistic $T$ (smallest of the two sums of ranks), its significance $(p)$, and the effect size $(r)$ were reported.

\section{RESULTS}

\section{Subjects}

A complete data set was available for nine participants. The physical characteristics of each of the nine subjects are displayed in Table 1.

\section{Kinematics}

Movement parameters are presented in Table 2. During the maximal reaching task with and without gravity compensation, the maximum elbow angle was significantly lower with gravity compensation (median $33.3^{\circ}$ ) than without gravity compensation (median $29.4^{\circ}$ ), $T=2, p=$ $0.021, r=-0.77$.

During the reach and retrieval task with gravity compensation, all subjects showed decreased elbow extension (range $0.1^{\circ}-11.0^{\circ}$ ). At the shoulder joint, seven subjects 
Table 1.

Physical characteristics of subjects $(N=9)$.

\begin{tabular}{|c|c|c|c|c|c|c|c|c|c|}
\hline \multirow{2}{*}{ Variable } & \multicolumn{9}{|c|}{ Subject ID Number } \\
\hline & 1 & 2 & 3 & 4 & 5 & 6 & 7 & 8 & 9 \\
\hline Sex & M & $\mathrm{M}$ & $\mathrm{M}$ & $\mathrm{M}$ & $\mathrm{F}$ & M & $\mathrm{F}$ & $\mathrm{M}$ & $\mathrm{M}$ \\
\hline Age (yr) & 28 & 55 & 47 & 59 & 39 & 40 & 26 & 53 & 36 \\
\hline Time Since Injury (mo) & 58 & 29 & 282 & 209 & 66 & 221 & 161 & 170 & 198 \\
\hline Motor Level of Lesion & C5 & C6 & C6 & C6 & C5 & C5 & C6 & C6 & C7 \\
\hline ASIA Impairment Scale & A & $\mathrm{C}$ & B & $\mathrm{D}$ & B & $\mathrm{C}$ & A & A & A \\
\hline \multicolumn{10}{|c|}{ ASIA Motor Score of Measured Arm (MRC score) } \\
\hline C5 (elbow flexors) & 4 & 5 & 5 & 5 & 4 & 5 & 5 & 5 & 5 \\
\hline C6 (wrist extensors) & 0 & 4 & 4 & 4 & 5 & 2 & 5 & 5 & 5 \\
\hline C7 (elbow extensors) & 0 & 2 & 0 & 5 & 4 & 4 & 0 & 0 & 3 \\
\hline C8 (finger extensors) & 0 & 0 & 0 & 4 & 1 & 0 & 0 & 0 & 0 \\
\hline
\end{tabular}

had decreased plane $\left(0.3^{\circ}-6.9^{\circ}\right)$ and six subjects had reduced angle of elevation $\left(0.1^{\circ}-15.1^{\circ}\right)$. The movement times increased in four subjects (range 0.1-0.4 s), decreased in two subjects $(0.2-0.4 \mathrm{~s})$, and remained the same in three subjects. None of these parameters differs significantly between movements performed with and without gravity compensation (elbow extension: $T=2, p=$ $0.214, r=-0.41$; shoulder plane of elevation: $T=3, p=$ $0.767, r=-0.10$; shoulder angle of elevation: $T=4, p=$ $0.515, r=-0.22$; and cycle duration: $T=2, p=0.484, r=$ $-0.23)$.

\section{Electromyography}

Based on the plotted smooth rectified sEMG (Figure 5) and calculated differences (in terms of percentage) in the areas under the curves (Table 2), we made three observations:

1. With gravity compensation, the amplitude of the sEMG decreased especially in the antigravity muscles. In six subjects, amplitude of the sEMG decreased in the descending part of the trapezius (range 17.5\%$60.6 \%)$ and increased in three subjects $(4.1 \%, 6.5 \%$, and $59.7 \%$ ). In all subjects, amplitude of the sEMG was decreased in the posterior part of deltoid (range: $12.8 \%-54.1 \%)$, the anterior part of deltoid (17.4\%$73.6 \%)$, and the long head of biceps (22.9\%-80.0\%).

2. In four subjects (identification numbers $1,3,7$, and 8 ) without triceps activity (Medical Research Council [MRC] score of 0), sEMG activity was recorded during flexion of the elbow.
3. In three of the five subjects with active triceps function (MRC score of at least 2), the amplitude of sEMG in the long head of triceps increased $(25.2 \%, 1.2 \%$, and $16.9 \%)$ and decreased in the other two subjects (16.4\% and $56.6 \%)$. On a group level, a significant difference between the conditions with and without gravity compensation was found for the following muscles: descending part of trapezius during reach: $T=1, p=$ 0.038, $r=-0.69$; posterior part of deltoid during reach: $T=$ $1, p=0.015, r=-0.81$, and during retrieval: $T=0, p=$ $0.008, r=-0.89$; and anterior part of deltoid and long head biceps for reach as well as retrieval: $T=0, p=$ $0.008, r=-0.89$.

Within subjects, the timing of muscle activation did not change visibly with gravity compensation. With respect to the patterns of timing between subjects, we found various different patterns. Some alternating activation patterns were found between agonists and antagonists. All subjects with at least some triceps function showed an alternating activation pattern between the long head of biceps and triceps (Figure 6(a)). We found a simultaneous activation pattern in four subjects between the activation of the anterior and posterior parts of the deltoid muscle (Figure 6(b)) and in six subjects between the anterior part of deltoid and pectoral muscles (Figure 6(c)).

Furthermore, the descending part of the trapezius was used in various different patterns. In one subject, an alternating activation pattern between the anterior and posterior parts of the deltoid occurred, and in another subject, an alternating activation pattern between the 
JRRD, Volume 47, Number 7, 2010

Table 2.

Influence of gravity compensation on kinematic parameters during maximal reaching task on kinematic and surface electromyography (sEMG) parameters during reach and retrieval task of participants $(N=9)$ with and without Freebal $(\mathrm{Fb})$.

\begin{tabular}{|c|c|c|c|c|c|c|c|c|c|c|}
\hline \multirow{2}{*}{ Task } & \multirow{2}{*}{ Fb } & \multicolumn{9}{|c|}{ Subject ID Number } \\
\hline & & 1 & 2 & 3 & 4 & 5 & 6 & 7 & 8 & 9 \\
\hline \multicolumn{11}{|l|}{ Maximal Reach } \\
\hline \multirow{2}{*}{ Elbow Angle $\left(^{\circ}\right)$} & No & 47.9 & 19.0 & 47.5 & 36.9 & 22.3 & 24.3 & 21.1 & 46.2 & 29.4 \\
\hline & Yes & 52.2 & 20.8 & 47.4 & 36.1 & 25.3 & 28.8 & 23.6 & 49.4 & 33.3 \\
\hline \multicolumn{11}{|l|}{ Reach and Retrieval } \\
\hline \multicolumn{11}{|c|}{ Angles of Elbow and Shoulder at Target Dot $\left({ }^{\circ}\right)$} \\
\hline \multirow{2}{*}{ Elbow Angle } & No & 47.5 & 29.0 & 47.8 & 54.9 & 40.4 & 25.7 & 43.1 & 56.7 & 36.6 \\
\hline & Yes & 57.5 & 29.4 & 58.8 & 64.0 & 47.5 & 32.9 & 43.2 & 65.3 & 39.6 \\
\hline \multirow{2}{*}{ Plane of Elevation } & No & -71.6 & -42.7 & -50.0 & -66.4 & -49.3 & -39.8 & -43.3 & -56.7 & -54.0 \\
\hline & Yes & -64.7 & -40.3 & -49.7 & -66.7 & -48.4 & -50.5 & -41.4 & -54.7 & -51.2 \\
\hline \multirow{2}{*}{ Angle of Elevation } & No & 30.6 & 23.0 & 37.8 & 51.3 & 29.1 & 27.2 & 44.6 & 44.7 & 40.4 \\
\hline & Yes & 15.5 & 30.3 & 34.2 & 40.5 & 31.8 & 32.2 & 35.3 & 44.6 & 39.5 \\
\hline \multicolumn{11}{|l|}{ Parameters of Movement Cycles } \\
\hline \multirow{2}{*}{ Cycle Duration (s) } & No & 2.7 & 2.1 & 1.4 & 2.4 & 1.3 & 1.6 & 1.5 & 2.9 & 1.3 \\
\hline & Yes & 3.1 & 2.2 & 1.4 & 2.0 & 1.3 & 1.6 & 1.6 & 2.7 & 1.4 \\
\hline \multirow{2}{*}{ Repetitions ( $n$ in $30 \mathrm{~s}$ ) } & No & 11 & 14 & 21 & 13 & 23 & 19 & 20 & 10 & 23 \\
\hline & Yes & 10 & 14 & 21 & 15 & 23 & 19 & 19 & 11 & 21 \\
\hline \multicolumn{11}{|c|}{ sEMG Parameters: Change of Area Under Curve (\%) ${ }^{*}$} \\
\hline Descending Part of Trapezius & - & -17.5 & -41.2 & 4.1 & -60.6 & -46.8 & -48.3 & 59.7 & 6.5 & -19.3 \\
\hline Posterior Part of Deltoid & - & -43.0 & -54.1 & -29.5 & -16.0 & -47.2 & -26.1 & -32.9 & -26.3 & -12.8 \\
\hline Anterior Part of Deltoid & - & -54.5 & -31.9 & -17.4 & -73.6 & -27.0 & -33.2 & -39.8 & -30.6 & -31.6 \\
\hline Pectoralis Major & - & -30.4 & -51.2 & -14.7 & -40.6 & -38.1 & -11.3 & -4.2 & -39.0 & 22.2 \\
\hline Long Head Biceps & - & -57.0 & -78.0 & -42.9 & -80.0 & -41.6 & -52.7 & -44.4 & -26.4 & -22.9 \\
\hline Lateral Head Triceps & - & -55.7 & 46.6 & -37.3 & -24.8 & -10.7 & 115.5 & -43.4 & -29.6 & -13.8 \\
\hline Long Head Triceps & - & -47.2 & 25.2 & -37.7 & 1.2 & -16.4 & -56.6 & 12.1 & -24.5 & 16.9 \\
\hline Latissimus Dorsi & - & -17.5 & -6.6 & -13.1 & -28.6 & -23.5 & -17.8 & -5.5 & 45.4 & -4.8 \\
\hline
\end{tabular}

*Negative value means decrease in area under curve during movement with Fb, compared with same movement without Fb.

ID = identification.

posterior parts of the deltoid solely. These two combinations were also observed in a simultaneous pattern: in one subject, the descending part of the trapezius and anterior and posterior parts of the deltoid were simultaneously activated, and in another subject, the descending part of the trapezius was activated with the posterior deltoid solely.

\section{DISCUSSION}

The objective of the present study was to study the influence of gravity compensation on kinematics and
sEMG characteristics of the upper limb during goaldirected movements of subjects with a CSCI.

With gravity compensation, most of the subjects showed less elbow extension and movement execution closer to the midline. Based on previous studies with stroke patients, one can expect that gravity compensation increases range of motion of the upper limb $[12,14]$ because of the positive effect on pathological muscle synergies between shoulder abduction and elbow flexion [14]. In patients with a CSCI, this pathological coupling does not occur. However, an effect on kinematics is expected because less muscle force is necessary to overcome 
(a)

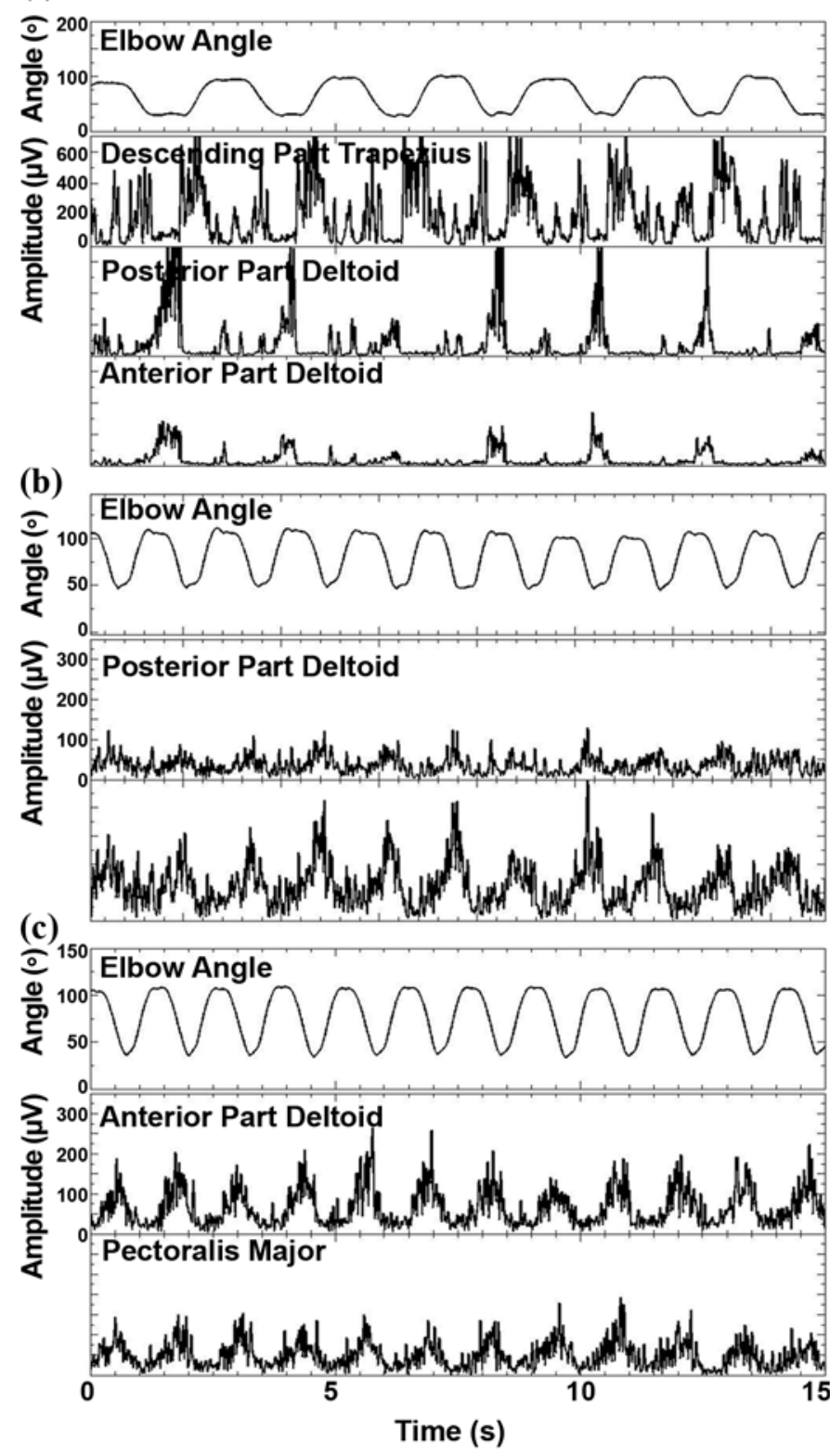

Figure 6.

Examples of muscle activation patterns and corresponding elbow angle: (a) Alternating activation pattern between biceps and triceps (subject identification [ID] number 2), (b) simultaneous pattern between anterior and posterior part of deltoid (subject ID number 3), and (c) simultaneous pattern between anterior deltoid and pectoralis major (subject ID number 11).

gravity. A larger part of the muscle force could be used to perform goal-directed movements, possibly leading to increased elbow extension during maximal reaching and more repetitions during reach and retrieval. However, the results of this study showed less elbow extension during maximal reaching with gravity compensation in seven subjects. During reach and retrieval with gravity compensation, all subjects showed less elbow extension and, in eight subjects, a decrease in shoulder angle and/or plane of elevation.

Plausible explanations could be given for these results. First, subjects with a CSCI who have a lack of triceps function use their anterior part of the deltoid and upper pectoral muscles to produce an isometric extension torque in their elbow [20] or make a trick movement with their shoulder muscles to achieve passive elbow extension [21]. They use gravity to maintain the arm in extension below the horizontal plane [22] and to perform a passive elbow extension with a trick movement. In both compensation strategies, gravity is used to maintain elbow extension. Therefore, movement execution with gravity compensation might decrease elbow extension. Second, during goal-directed movements without gravity compensation, subjects use a large part of the preserved muscle force to hold the arm against gravity. If the primary agonists alone are not capable of generating the required anteflexion and extension torques, additional agonist muscles are recruited [23]. For example, the middle part of the deltoid might contribute to lift the arm, if the anterior part of the deltoid cannot generate enough force. The middle part of the deltoid also has an abduction function that can result in a reaching movement not truly in the sagittal plane [23]. Third, because of a decreased plane of elevation, the hand moves more in a direct line to the target dot. If the arm is extended closer to the midline, less elbow extension and angle of elevation are necessary to reach the target dot. Finally, with gravity compensation, the pectoral muscles can move the arm more easily to a position in front of the patient because the weight of the arm is counteracted.

The results of the sEMG data during the reach and retrieval task showed a decrease in sEMG activity during movements with the use of the Freebal, particularly in muscles that counteracted gravity, while timing remained unaffected. The results confirmed our presumption based on previous studies with nondisabled elderly [10] and stroke patients $[11,13,15]$ that also showed a decreased sEMG in antigravity muscles and unaffected timing. Remarkably, despite subjects with an MRC score of 0 in the triceps, sEMG activity was seen mainly during elbow flexion. A plausible explanation for this sEMG activity is stretch or cocontraction. In the sEMG signal, however, 
one cannot differentiate between activity because of stretch and voluntary motor activity [24].

A large variety in muscle activation patterns was seen between subjects because of heterogeneity of the study population. After a CSCI, the functional anatomy of the upper limb had to be redefined. Muscle synergies as seen in nondisabled subjects are often inappropriate for subjects with a CSCI [20]. The central nervous system is challenged to use a motor strategy to adjust to the new functional anatomy and biomechanics, with a reduced repertoire of innervated muscles to deal with the mechanics [21], leading to different movement patterns between subjects with a CSCI [20].

To our knowledge, our study was the first explorative study about the effect of gravity compensation on kinematics and sEMG in subjects with a CSCI. Another type of arm support by subjects with a CSCI was studied by Atkins et al. [7]. They reported about the effect of mobile arm support on ADLs. Based on Delphi questionnaires, they concluded that some ADLs were possible with the use of a mobile arm support, which without the use of such a device, patients with very weak biceps and deltoid muscles were unable to perform.

Besides being used for compensating lost functions, gravity compensation can be used for training purposes. Further studies should be performed with a larger population because of the small effect size, especially on kinematic parameters, and should be able to test the following hypotheses: (1) patients with an MRC score of at least 2 in the triceps muscle can train their primary agonists of the shoulder and elbow in goal-directed movements more intensively and, (2) for patients without active triceps function (MRC score of 0 or 1 ), gravity compensation may not seem useful to train extension movements because they perform these movements with the use of gravity. However, gravity compensation might be beneficial for training muscles required to cross the midline or to perform bimanual tasks. Also, the influence of gravity compensation on the patients' ability to stabilize the shoulder in a certain position would be an interesting parameter.

\section{CONCLUSIONS}

This explorative study showed that gravity compensation influenced the kinematics and amplitude of the sEMG of the upper limb during goal-directed movements in CSCI. A larger study is needed to firmly conclude whether training with gravity compensation is clinically relevent.

\section{ACKNOWLEDGMENTS}

\section{Author Contributions:}

Study concept and design: G. J. Snoek, M. Kouwenhoven, A. V. Nene, M. J. A. Jannink.

Recruitment of study population: G. J. Snoek, M. Kouwenhoven, A. V. Nene.

Data collection and analysis: M. G. M. Kloosterman, M. Kouwenhoven.

Interpretation of data: M. G. M. Kloosterman, G. J. Snoek, M. Kouwenhoven, A. V. Nene, M. J. A. Jannink.

Drafting of manuscript: M. G. M. Kloosterman.

Critical revision of manuscript: G. J. Snoek, M. Kouwenhoven, A. V. Nene, M. J. A. Jannink.

Financial Disclosures: The authors have declared that no competing interests exist.

Funding/Support: This material was based on work supported by the Ministry of Economic Affairs (EZ) Overijssel and Gelderland, the Netherlands, grant 1-5160. The study sponsor was not involved in any aspect of this research.

Additional Contributions: Ms. Kloosterman is now only affiliated with Roessingh Research and Development, Enschede, the Netherlands.

Institutional Review: The study was approved by the local medical ethics committee. Subjects provided written informed consent before being admitted to the study.

Participant Follow-Up: The authors do not plan to inform participants of the publication of this study.

\section{REFERENCES}

1. Kirshblum S, Ho CH, House JG, Druin E, Nead C, Drastal S. Rehabilitation of spinal cord injury. In: Kirshblum S, Campagnolo DI, DeLisa JA, editors. Spinal cord medicine. Philadelphia (PA): Lippincott Williams \& Wilkins; 2001. p. 275-98.

2. Snoek GJ, IJzerman MJ, Hermens HJ, Maxwell D, BieringSorensen F. Survey of the needs of patients with spinal cord injury: Impact and priority for improvement in hand function in tetraplegics. Spinal Cord. 2004;42(9):526-32. [PMID: 15224087] DOI:10.1038/sj.sc.3101638

3. Jacobs PL, Nash MS. Exercise recommendations for individuals with spinal cord injury. Sports Med. 2004;34(11): 727-51. [PMID: 15456347] DOI:10.2165/00007256-200434110-00003

4. Kloosterman MG, Snoek GJ, Jannink MJ. Systematic review of the effects of exercise therapy on the upper 
extremity of patients with spinal-cord injury. Spinal Cord. 2009;47(3):196-203. [PMID: 18825160]

DOI:10.1038/sc.2008.113

5. Schmidt RA, Lee TD. Condition of practice. In: Schmidt RA, Lee TD, editors. Motor control and learning: A behavioural emphasis. 4th ed. Champaign (IL): Human Kinetics; 2005. p. 321-63.

6. Powers SK, Howley ET. The physiology of training: Effect on VO2 max, performance, homeostasis, and strength. In: Powers SK, Howley ET, editors. Exercise physiology, theory and application to fitness and performance. 5th ed. New York (NY): McGraw-Hill; 2004. p. 249-75.

7. Atkins MS, Baumgarten JM, Yasuda YL, Adkins R, Waters RL, Leung P, Requejo P. Mobile arm supports: Evidencebased benefits and criteria for use. J Spinal Cord Med. 2008; 31(4):388-93. [PMID: 18959356]

8. Prange GB, Jannink MJ, Groothuis-Oudshoorn CG, Hermens HJ, IJzerman MJ. Systematic review of the effect of robot-aided therapy on recovery of the hemiparetic arm after stroke. J Rehabil Res Dev. 2006;43(2):171-84. [PMID: 16847784] DOI:10.1682/JRRD.2005.04.0076

9. Kwakkel G, Kollen BJ, Krebs HI. Effects of robot-assisted therapy on upper limb recovery after stroke: A systematic review. Neurorehabil Neural Repair. 2008;22(2):111-21. [PMID: 17876068$]$ DOI:10.1177/1545968307305457

10. Prange GB, Kallenberg LA, Jannink MJ, Stienen AH, Van der Kooij H, IJzerman MJ, Hermens HJ. Influence of gravity compensation on muscle activity during reach and retrieval in healthy elderly. J Electromyogr Kinesiol. 2009;19(2): e40-49. [PMID: 17911029]

DOI:10.1016/j.jelekin.2007.08.001

11. Prange GB, Jannink MJ, Stienen AH, Van der Kooij H, IJzerman MJ, Hermens HJ. Influence of gravity compensation on muscle activation patterns during different temporal phases of arm movements of stroke patients. Neurorehabil Neural Repair. 2009;23(5):478-85. [PMID: 19190089] DOI:10.1177/1545968308328720

12. Stienen AH, Van der Helm FC, Prange GB, Jannink MJ, Van der Kooij H. Effects of gravity compensation on the range-of-motion of the upper extremities in robotic rehabilitation after stroke. In: Proceedings of the International Shoulder Group (ISG). 2006 Oct 9-10; Chicago, IL; [about 4 screens]. Available from: http://www.arnostienen.net/ articles/stienen06.pdf/.

13. Prange GB, Stienen AH, Jannink MJ, Van der Kooij H, IJzerman MJ, Hermens HJ. Increased range of motion and decreased muscle activity during maximal reach with gravity compensation in stroke patients. In: Proceedings of the 2007 IEEE 10th International Conference on Rehabilitation Robotics; 2007 Jun 13-15; Noordwijk aan Zee, the Nether- lands. Piscataway (NJ): IEEE Press. p. 467-71. DOI:10.1109/ICORR.2007.4428467

14. Dewald J, Yao J. The effect of generating anti-gravity shoulder torques on upper limb discoordination following hemiparetic stroke. In: Proceedings of the ISB XXth Congress-ASB 29th Annual Meeting; 2005 Jul 31-Aug 5. Cleveland, OH. International Society of Biomechanics. 973 p. Available from: http://isbweb.org/o/content/view/280/1/.

15. Jannink MJ, Prange GB, Stienen AH, Van der Kooij H, Kruidbosch JM, IJzerman MJ, Hermens HJ. Reduction of muscle activity during repeated reach and retrieval with gravity compensation in stroke patients. In: Proceedings of the 2007 IEEE 10th International Conference on Rehabilitation Robotics; 2007 Jun 13-15; Noordwijk aan Zee, the Netherlands. Piscataway (NJ): IEEE Press. p. 472-76. DOI:10.1109/ICORR.2007.4428468

16. Maynard FM Jr, Bracken MB, Creasey G, Ditunno JF Jr, Donovan WH, Ducker TB, Garber SL, Marino RJ, Stover SL, Tator CH, Waters RL, Wilberger JE, Young W. International standards for neurological and functional classification of spinal cord injury. American Spinal Injury Association. Spinal Cord. 1997;35(5):266-74.

[PMID: 9160449]

DOI:10.1038/sj.sc.3100432

17. Stienen AH, Hekman EE, Van der Helm FC, Prange GB, Jannink MJ, Aalsma AM, Van der Kooij H. Freebal: Dedicated gravity compensation for the upper extremities. In: Proceedings of the 2007 IEEE 10th International Conference on Rehabilitation Robotics; 2007 Jun 13-15; Noordwijk aan Zee, the Netherlands. Piscataway (NJ): IEEE Press. p. 804-8. DOI:10.1109/ICORR.2007.4428517

18. Wu G, Van der Helm FC, Veeger HE, Makhsous M, Van Roy P, Anglin C, Nagels J, Karduna AR, McQuade K, Wang X, Werner FW, Buchholz B; International Society of Biomechanics. ISB recommendation on definitions of joint coordinate systems of various joints for the reporting of human joint motion-Part II: Shoulder, elbow, wrist and hand. J Biomech. 2005;38(5):981-92. [PMID: 15844264] DOI:10.1016/j.jbiomech.2004.05.042

19. Hermens HJ, Freriks B, Merletti R, Stegeman D, Blok J, Tau G, Disselhorst-Klug C, Hagg G. SENIAM: European recommendations for surface electromyography. Results of the SENIAM project. 2nd ed. Enschede (the Netherlands): Roessingh Research and Development; 1999.

20. Marciello MA, Herbison GJ, Cohen ME, Schmidt R. Elbow extension using anterior deltoids and upper pectorals in spinal cord-injured subjects. Arch Phys Med Rehabil. 1995;76(5):426-32. [PMID: 7741612] DOI:10.1016/S0003-9993(95)80571-0

21. Koshland GF, Galloway JC, Farley B. Novel muscle patterns for reaching after cervical spinal cord injury: A case for motor redundancy. Exp Brain Res. 2005;164(2):133-47. 
[PMID: 16028034$]$

DOI:10.1007/s00221-005-2218-9

22. Acosta AM, Kirsch RF, Van der Helm FC. Three-dimensional shoulder kinematics in individuals with C5-C6 spinal cord injury. Proc Inst Mech Eng H. 2001;215(3):299-307. [PMID: 11436273] DOI:10.1243/0954411011535894

23. McCrea PH, Eng JJ, Hodgson AJ. Saturated muscle activation contributes to compensatory reaching strategies after stroke. J Neurophysiol. 2005;94(5):2999-3008.

[PMID: 16014786]

DOI:10.1152/jn.00732.2004

24. Moritani T, Stegeman D, Merletti R. Basic physiology and biophysics of EMG signal regeneration. In: Merletti R, Parker PA, editors. Electromyography. physiology, engineering, and noninvasive applications. New York (NY): John Wiley \& Sons; 2004. p. 1-25. DOI:10.1002/0471678384

Submitted for publication February 9, 2010. Accepted in revised form June 1, 2010.

This article and any supplementary material should be cited as follows:

Kloosterman MGM, Snoek GJ, Kouwenhoven M, Nene AV, Jannink MJA. Influence of gravity compensation on kinematics and muscle activation patterns during reach and retrieval in subjects with cervical spinal cord injury: An explorative study. J Rehabil Res Dev. 2010;47(7): 617-28.

DOI:10.1682/JRRD.2010.02.0014 